\title{
Novel PDGFRB rearrangement in multifocal infantile myofibromatosis is tumorigenic and sensitive to imatinib
}

\author{
Mohammed Hassan, ${ }^{1}$ Erin Butler, ${ }^{1,3}$ Raphael Wilson, ${ }^{1}$ Angshumoy Roy, ${ }^{4}$ \\ Yanbin Zheng, ${ }^{1}$ Priscilla Liem, ${ }^{1}$ Dinesh Rakheja, ${ }^{5}$ Dean Pavlick, ${ }^{6}$ Lauren L. Young, ${ }^{6,7}$ \\ Mark Rosenzweig, ${ }^{6}$ Rachel Erlich, ${ }^{6}$ Siraj M. Alii, ${ }^{6}$ Patrick J. Leavey, ${ }^{1,2,3}$ \\ D. Williams Parsons, ${ }^{4}$ Stephen X. Skapek, ${ }^{1,2,3}$ and Theodore W. Laetsch ${ }^{1,2,3}$ \\ ${ }^{1}$ Division of Hematology/Oncology, Departments of Pediatrics, ${ }^{2}$ Harold C. Simmons Comprehensive Cancer \\ Center, University of Texas Southwestern Medical Center, Dallas, Texas 75390, USA; ${ }^{3}$ Pauline Allen Gill Center \\ for Cancer and Blood Disorders, Children's Health, Dallas, Texas 75235, USA; ${ }^{4}$ Baylor College of Medicine, \\ Houston, Texas 77030, USA; ${ }^{5}$ Department of Pathology, University of Texas Southwestern Medical Center, \\ Dallas, Texas 75390, USA; ${ }^{6}$ Foundation Medicine, Inc, Cambridge, Massachusetts 02141, USA; ${ }^{7}$ Beam \\ Therapeutics, Cambridge, Massachusetts 02139, USA
}

Corresponding author: ted.laetsch@utsouthwestern.edu

(c) 2019 Hassan et al. This article is distributed under the terms of the Creative Commons Attribution-NonCommercial License, which permits reuse and redistribution, except for commercial purposes, provided that the original author and source are credited.

Ontology term: neoplasm of the skin

Published by Cold Spring Harbor Laboratory Press

doi:10.1101/mcs.a004440
Abstract Infantile myofibromatosis (IM) is an aggressive neoplasm composed of myofibroblast-like cells in children. Although typically localized, it can also present as multifocal disease, which represents a challenge for effective treatment. IM has previously been linked to activating somatic and germline point mutations in the PDGFR $\beta$ tyrosine kinase encoded by the PDGFRB gene. Clinical panel-based targeted tumor sequencing of a tumor from a newborn with multifocal IM revealed a novel PDGFRB rearrangement, which was reported as being of unclear significance. Additional sequencing of cDNA from tumor and germline DNA confirmed a complex somatic/mosaic PDGFRB rearrangement with an apparent partial tandem duplication disrupting the juxtamembrane domain. Ectopic expression of cDNA encoding the mutant form of PDGFRB markedly enhanced cell proliferation of mouse embryo fibroblasts (MEFs) compared to wild-type PDGFRB and conferred tumor-forming capacity on nontumorigenic 10T1/2 fibroblasts. The mutated protein enhanced MAPK activation and retained sensitivity to the PDGFR $\beta$ inhibitor imatinib. Our findings reveal a new mechanism by which PDGFRB can be activated in IM, suggest that therapy with tyrosine kinase inhibitors including imatinib may be beneficial, and raise the possibility that this receptor tyrosine kinase might be altered in a similar fashion in additional cases that would similarly present annotation challenges in clinical DNA sequencing analysis pipelines.

[Supplemental material is available for this article.]

\section{INTRODUCTION}

Infantile myofibroma is a relatively rare form of soft tissue neoplasm that is primarily diagnosed in children of $<12$ mo of age (Parham 2018). The multifocal disease is known as infantile myofibromatosis (IM), which if untreated carries a mortality rate of $70 \%$ when lesions are present in viscera (Wiswell et al. 1988; Day et al. 2002; Mashiah et al. 2014; Weaver et al. 2015; Wu et al. 2015). Historically, treatment for myofibromatosis ranges from expectant management or surgical resection alone to the application of systemic, low-dose chemotherapy for those with multifocal or unresectable disease (Azzam et al. 2009; Mashiah et al. 2014; Weaver et al. 2015; Parham 2018). This neoplasm also presents with circumscribed lesions 
COLD SPRING HARBOR Molecular Case Studies
PDGFRB rearrangement in infantile myofibromatosis with histologic appearance of spindled cells and immunohistochemical staining patterns that demonstrate similarities between IM and infantile fibrosarcoma (Alaggio et al. 2008; Parham 2018).

Molecular genetic studies have recently identified activating mutations in platelet-derived growth factor $\beta$ (PDGFR $\beta$ ) in most IM cases. PDGFR $\beta$ is a transmembrane receptor tyrosine kinase encoded by the PDGFRB gene (Forsberg et al. 1993; Hellström et al. 1999; Hoch and Soriano 2003; Tallquist and Kazlauskas 2004; Andrae et al. 2008). The PDGFRB gene is primarily expressed in cells of mesenchymal origin, including smooth muscle cells, and analyses of genetically engineered mouse models show PDGFR to be essential for embryonic development in part by controlling perivascular cell accumulation/localization (Soriano 1994; Hoch and Soriano 2003). The PDGF signaling pathway has long been recognized to play a critical role in propelling the cell division cycle from $\mathrm{G}_{1}$ phase into $\mathrm{S}$ phase (Pardee 1989). Deregulated activation of PDGFR $\beta$ has been identified in human cancers, including by a rearrangement-generated fusion protein, originally described in a child with chronic myelomonocytic leukemia that harbored a TEL-PDGFR fusion (Golub et al. 1994) and subsequently in RABEP1-PDGFRB and CEV14-PDGFRB fusions in myelogenous leukemia (Abe et al. 1997; Magnusson et al. 2001). PDGFR $\beta$ is also activated by autocrine/paracrine stimulation through increased expression of its ligand, PDGF-B, exemplified by the COL1A1-PDGFB translocation in dermatofibrosarcoma protuberans (Wang et al. 1999; McArthur 2006). Few human cancers have been described to harbor kinase-activating PDGFRB mutations, with the exception of IM, in which both somatic and germline missense mutations in PDGFRB have been identified (Cheung et al. 2013; Martignetti et al. 2013; Agaimy et al. 2017; Arts et al. 2017; Murray et al. 2017; Pond et al. 2018). Germline PDGFRB gain-of-function mutations appear to underlie the majority of familial cases (eight of nine unrelated families in one series) (Martignetti et al. 2013), and a substantial fraction of patients with sporadic multifocal disease have either germline, somatic, or mosaic gainof-function mutations (Arts et al. 2017). The majority of the PDGFRB mutations described to date in IM alter the juxtamembrane domain, defeating an auto-inhibitory feedback loop, or alter the kinase domain, presumably resulting in constitutive activation (Agaimy et al. 2017; Arts et al. 2017).

In this article, we present the case of a newborn child with seemingly sporadic, multifocal IM. Clinical molecular genetic analysis of the tumor revealed a novel PDFGRB rearrangement initially reported as a variant of unknown clinical significance. Additional molecular genetic analyses and in vitro functional studies demonstrate the oncogenic activity of this newly recognized mutant allele. To our knowledge, this is the first case of a rearrangement in PDFGRB reported in IM and represents a novel mechanism of PDGFR $\beta$ activation in this disease.

\section{RESULTS}

\section{Clinical Case Presentation}

A 9-day-old African-American girl presented to the pediatric surgery team for evaluation of a well-circumscribed, nontender, and firm soft tissue mass on the anterior abdominal wall. The mass was noted at birth but was undetected on prenatal ultrasound evaluations. Similar subcutaneous nodules were also noted on the upper back and left hip. The full-term child, born after an unremarkable prenatal course, was in otherwise good health. An abdominal ultrasound on day of life 1 showed the left upper quadrant soft tissue mass to measure $1.9 \mathrm{~cm} \times$ $1.2 \mathrm{~cm} \times 2.7 \mathrm{~cm}$ and confirmed its location in the subcutaneous tissue. A small focus of vascular flow was thought to be consistent with a hemangioma or congenital vascular anomaly. Following a period of observation, abdominal MRI at $\sim 2$ mo of age revealed multiple, rimenhancing lesions within the abdomen and pelvis (Fig. 1A). These included both osseous 
COLD SPRING HARBOR Molecular Case Studies

PDGFRB rearrangement in infantile myofibromatosis

A

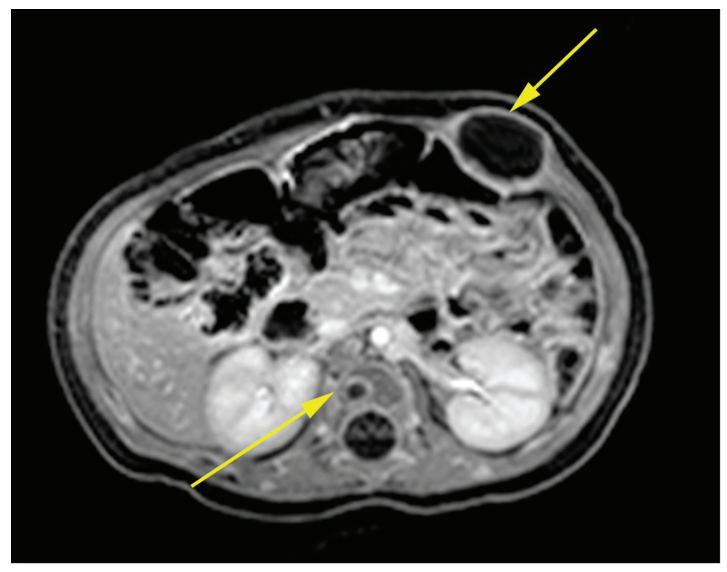

B

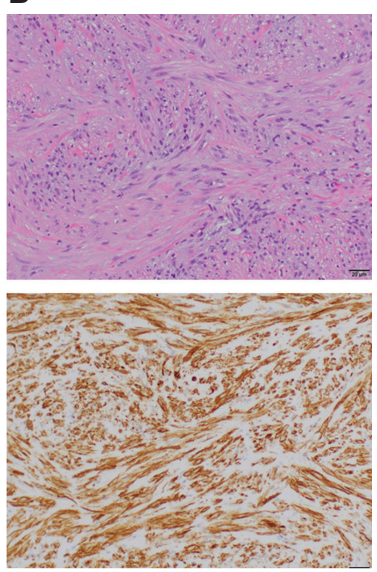

Figure 1. Tumor analysis and classification. (A) Postcontrast T1-weighted MRI demonstrates multiple rim-enhancing masses in the abdominal wall musculature and vertebral body. (B) Histopathologic examination of a biopsy from the abdominal wall mass shows a myofibroma. (Top) Hematoxylin and eosin, 200x magnification: (bottom) smooth muscle actin immunostain, 200× magnification.

and muscular lesions and one within the pancreatic head. An additional 10-mm lesion was noted in the left ventricular free wall on echocardiogram. The radiographic differential diagnosis of these lesions included infection, neurofibroma, multifocal Langerhans cell histiocytosis, metastatic neuroblastoma, and IM.

The child underwent an incisional biopsy of the left upper quadrant subcutaneous lesion, which had remained unchanged in appearance since birth. Intraoperatively, the mass was noted to be cystic and fused to the anterior abdominal wall, which prevented a complete excision without excessive morbidity. Gross pathologic analysis revealed a tan-pink to tanwhite, firm, rubbery mass. Light microscopy revealed bland, medium-sized, round to spindled cells with vacuolated nuclei arranged in a fascicular pattern and rare mitotic figures in a collagenous fibromyxoid stromal background. Immunohistochemical stains were performed, and the tumor stained positive for $\beta$-catenin (cytoplasmic only) and smooth muscle actin (Fig. 1B; and data not shown). These pathology studies and the clinical presentation were sufficient to make a diagnosis of $\mathrm{IM}$. The child was treated with vinblastine and methotrexate chemotherapy and had a stable disease at 13 mo of age, after 9 mo of therapy. The child has since been lost to follow-up. Whether vinblastine/methotrexate contributed to the disease stabilization is not clear.

\section{Molecular Genetic Analyses}

Formalin-fixed, paraffin-embedded tissue samples from the diagnostic specimen were analyzed using FoundationOne Heme, a commercial hybrid capture-based next-generation sequencing (NGS) assay. Sequencing revealed a CDKN2A missense variant predicted to influence the amino acid sequence of $p 14^{\mathrm{ARF}}$ (S73R) but not p16 ${ }^{\mathrm{INK} 4 \mathrm{~A}}$ (R58R) and a rearrangement of PDGFRB reported as a variant of uncertain significance (Table 1). As the significance of $\mathrm{p} 14^{\mathrm{ARF}-\mathrm{S} 73 R}$ is uncertain (di Tommaso et al. 2009), we chose to focus on the PDGFRB rearrangement. Further manual review of the NGS data for PDGFRB suggested a complicated deletion/duplication in which $13 \mathrm{nt}$ are deleted from within exon 12 (breakpoints Chr 5: 149,505,080, Chr 5:149,505,067) and replaced by a duplicated portion of intron 14 and exon 15 (breakpoints intron 14-Chr 5: 149,502,780, exon 15-Chr 5: $149,502,629$ ) (Fig. 2A,B). Sanger sequencing of segments of genomic DNA and cDNA 


\begin{tabular}{|c|c|c|c|c|c|c|c|}
\hline Gene & Chromosome & HGVS DNA reference & HGVS protein reference & Variant type & $\begin{array}{l}\text { Predicted effect } \\
\text { (substitution, } \\
\text { deletion, etc.) }\end{array}$ & $\begin{array}{l}\text { dbSNP/ } \\
\text { dbVar ID }\end{array}$ & $\begin{array}{c}\text { Genotype } \\
\text { (heterozygous/ } \\
\text { homozygous) }\end{array}$ \\
\hline PDGFRB & Chr 5 & $\begin{array}{c}\text { NM_002609:c.1736_2024- } \\
\text { 17del1747_2160dup }\end{array}$ & $\begin{array}{l}\text { NP_002600.1: } \\
\text { P.LYS559ASPFSTER569 }\end{array}$ & $\begin{array}{l}\text { Insertion/ } \\
\text { deletion }\end{array}$ & Frameshift & N/A & Heterozygous \\
\hline CDKN2A & Chr 9 & $\begin{array}{l}\text { NM_058195:c.217A >C } \\
\text { NM_000077:c.174A>C } \\
\text { NM_001195132: } \\
\text { c.174A>C } \\
\text { NM_058197:c.*97A>C }\end{array}$ & $\begin{array}{l}\text { NP_478102.2:p.Ser73Arg } \\
\text { NP_000068.1:p.Arg58= } \\
\text { NP_001182061.1: } \\
\text { p.Arg58= }\end{array}$ & $\begin{array}{l}\text { Single- } \\
\text { nucleotide } \\
\text { variant }\end{array}$ & $\begin{array}{l}\text { Substitution/ } \\
\text { synonymous/UTR }\end{array}$ & rs201208890 & Heterozygous \\
\hline
\end{tabular}

amplified by PCR confirmed the presence of this rearrangement in tumor which was not identified in germline DNA obtained from peripheral blood mononuclear cells suggesting a somatic or germline mosaic event not affecting hematopoietic precursors (Supplemental Fig. 2). On the mRNA level, the $5^{\prime}$ end of exon 12, joined to an intronic sequence from intron 14 and lacking the $3^{\prime}$ splice donor site, is spliced out of the transcript, resulting in a net replacement of $73 \mathrm{nt}$ of exon 12 of the PDGFRB transcript by $136 \mathrm{nt}$ of PDGFRB exon 15

A

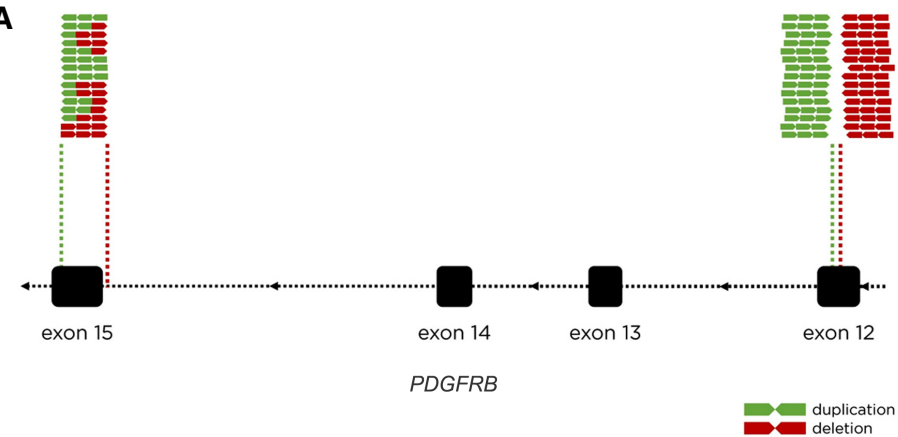

C

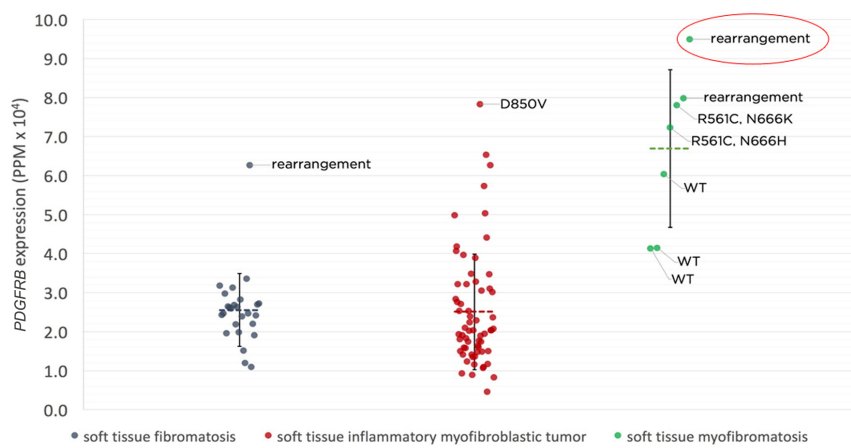

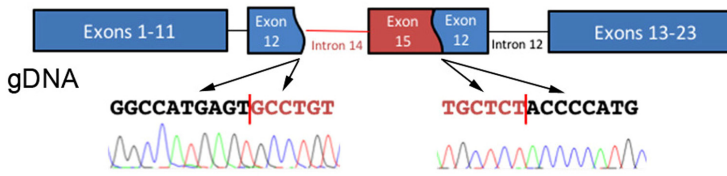

cDNA

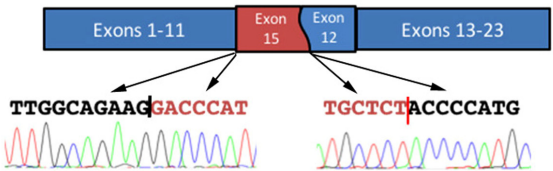

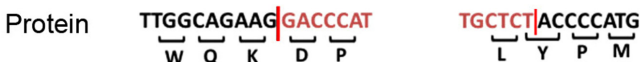

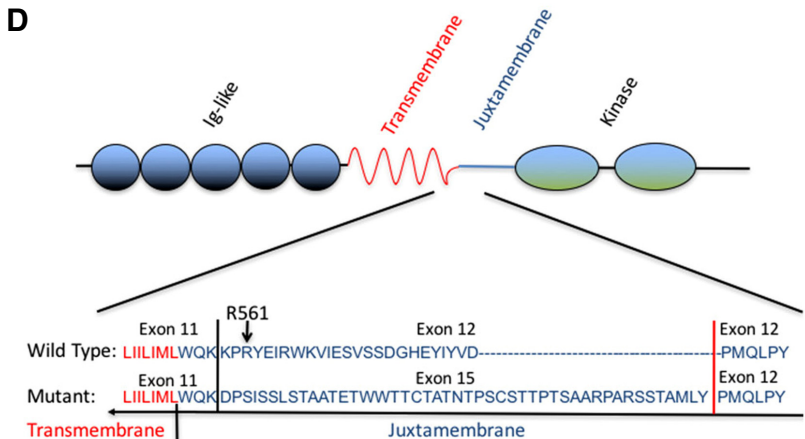

Figure 2. Sequencing and mapping of the gene rearrangement. (A) Complex PDGFRB rearrangement is detected by next-generation sequencing (NGS). The rearrangement was detected in DNA and RNA by NGS but is difficult to ascertain because of event complexity. (B) PDGFRB rearrangement predicted by NGS is confirmed by Sanger sequencing of genomic DNA (gDNA) and RNA (cDNA) from tumor. (C) PDGFRB is highly expressed in RNA-seq data from the patient's tumor (circled) compared to other cases of IM with and without activating PDGFRB point mutations. (D) Rearrangement results in the replacement of a portion of the juxtamembrane domain of PDGFR $\beta$ by a novel amino acid sequence derived from a portion of exon 15 read out-of-frame. The wild-type kinase domain is retained. 
(Fig. 2D). In the resulting putative PDGFR $\beta$ protein, 25 amino acids of the auto-inhibitory juxtamembrane domain are replaced by 46 amino acids generated by reading exon 15 of PDGFRB out-of-frame. The predicted amino acid sequence reverts to the wild-type reading frame at the junction between exons 15 and 12; hence, the kinase domain is intact and remains in-frame. Notably, this alteration eliminates a portion of the juxtamembrane domain, including the arginine residue at position 561, which has been reported to form a salt bridge that tethers the auto-inhibitory juxtamembrane domain to the kinase domain, facilitating inhibition of kinase activity (Toffalini and Demoulin 2010). Interestingly, normalized PDGFRB mRNA expression in this tumor (IM-P ${ }^{\mathrm{ITD}}$ ) was higher than the PDGFRB expression in three analyzed IM cases lacking PDGFRB alterations (IM-P $\left.{ }^{\mathrm{wt}}\right)$, two IM cases harboring PDGFRB missense mutations but no rearrangements (IM-P(mut), and any of the analyzed fibromatosis (FM) or inflammatory myofibroblastic tumor (IMT) cases in the Foundation Medicine database (Fig. 2C). Although our mRNA expression analysis did not distinguish between the mutant and wild-type transcripts, taken together, our findings suggest this IM tumor harbors a pathogenic PDGFRB complex rearrangement accompanied by high levels of PDGFRB mRNA expression, suggesting that $P D G F R B$ activation is an oncogenic driver in this IM tumor.

\section{Functional Analyses of the Mutant PDGFRB Variant}

We generated lentiviral expression vectors driving expression of GFP only (CTL) or GFP and either PDGFR $\beta$ (P-WT) or the PDGFR $\beta-\triangle$ Ex12 mutant CDNA identified in this patient (P-Ex12); vectors expressing GFP only served as a control. Following transduction of MEFs derived from Pdgfrb $^{-1-}$ mice at a $\mathrm{MOI}$ of 1 , we used RT-PCR and western blotting to show expression of each form (Fig. 3A-C) and found higher levels of phospho-p44/p42 MAPK in cells transduced by P-Ex12 than in cells transduced by P-WT, despite lower levels of PDGFR $\beta$ protein in P-Ex12 transduced cells (Fig. $3 C$ ). We studied the impact of their expression on the capacity of the MEFs to form colonies when cultivated at low density on tissue culture plates. After $14 \mathrm{~d}$, those assays showed that cells expressing P-Ex12 had increased colony formation compared with both P-WT and control vector expressing cells (Fig. 3D,E; $t$-test; $P<0.05$ ). Consistent with conferring a substantial growth advantage, our capacity to serially propagate $\mathrm{Pdgfrb}^{-/-}$MEFs expressing either CTL or PDGFR $\beta$ diminished as they approached passage number 7. In contrast, P-Ex12-expressing Pdgfrb ${ }^{-1-}$ MEFs continued unabated through passage number 25 , at which time we concluded the experiment.

Reasoning that functional advantage of PDGFR $\beta-\Delta \mathrm{E} \times 12$ might be exaggerated within a $\mathrm{Pdgfrb}^{-/}$background, we carried out similar experiments using 10T1/2 fibroblasts, a wellcharacterized fibroblast line originally derived from C3H mouse embryos (Reznikoff et al. 1973); the line has biallelic deletion of the Cdkn2a gene (SX Skapek, unpubl.), an event recognized to frequently occur in immortalized mouse fibroblasts (Kamijo et al. 1997). Using primers that amplify both mouse and human forms of PDGFRB CDNA, RT-PCR showed the expression of endogenous as well as the ectopic transcripts (Fig. 4A). Western blotting for PDGFR $\beta$ showed increased expression of the receptor in transduced cells with the level being approximately equal for wild-type PDGFR $\beta$ and P-Ex12, detected at $14 \mathrm{~d}$ following transduction (Fig. 4B). Western blotting also showed phospho-p44/p42 MAPK, known to be enhanced by PDGFR $\beta$ signaling (Andrae et al. 2008), was increased in cells with ectopic PDGFR $\beta$, with higher levels of phosphorylation seen in cells transduced by P-Ex12 than in cells transduced by P-WT, despite the latter exhibiting higher levels of total PDGFR $\beta$ protein (Fig. 4B).

Despite increased phospho-p44/p42 MAPK in P-Ex12-transduced 10T1/2 cells, we could not detect increased cell accumulation in the low-density plating assay, perhaps because the cells are already immortalized because of biallelic Cdkn2 deletion ( $\mathrm{MH}$ and SXS; negative data not shown). Nevertheless, we tested whether P-Ex12 might confer tumor-forming capacity by implanting cells transduced with control lentiviral vectors or vectors 

A P

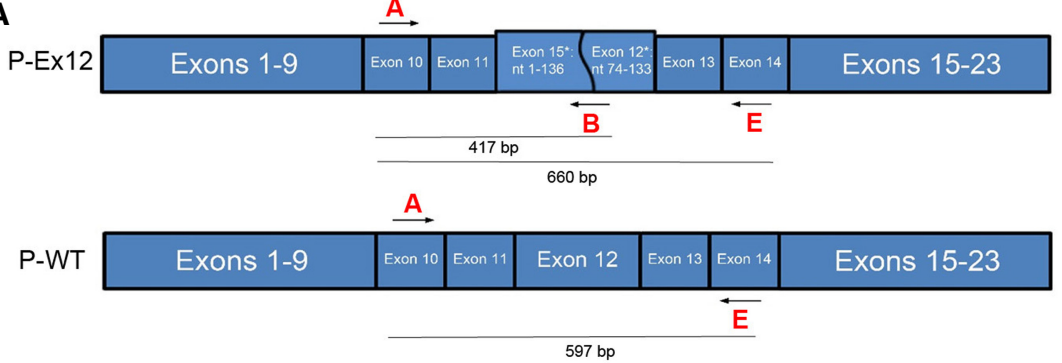

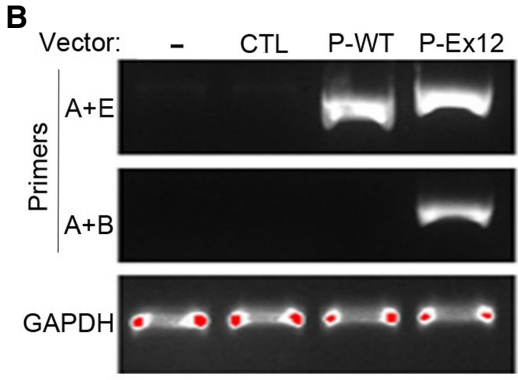

D

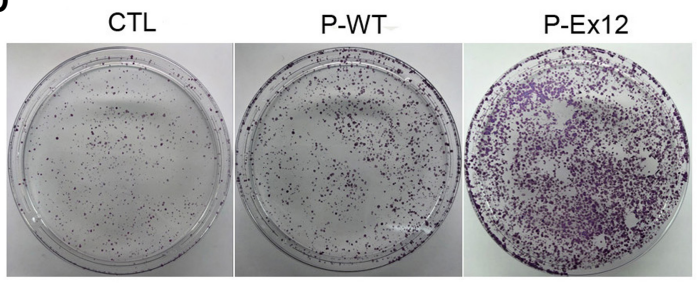

C

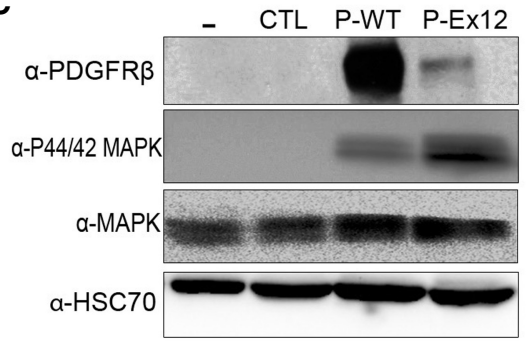

E

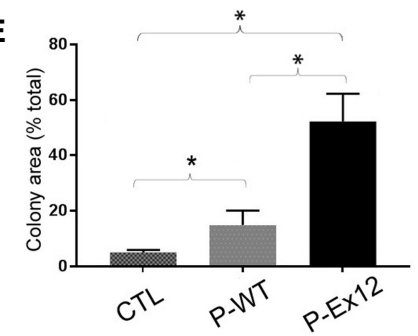

Figure 3. Functional evaluation of the rearrangement using PDGFRB-null mouse embryonic fibroblasts. (A) Diagram shows primers amplification for both wild-type PDGFRB (WT) and PDGFRB bearing the rearrangement identified in this patient's tumor (P-Ex12). (B) RT-PCR of PDGFRB-null mouse embryonic fibroblasts (MEFs) transduced with lentivirus expressing GFP only (CTL), P-WT, or P-Ex12. (C) A representative western blot of PDGFRB-null mouse embryonic fibroblasts that demonstrates expression of PDGFRB in P-WT- and P-Ex12-transduced cells and increased expression of phospho-p44/42 MAPK of cells transduced with P-Ex12 as compared to P-WT- and CTL-expressing mouse embryonic fibroblasts. (D) Photographs of colony formation assay of MEFs plated at low density show increased colony formation in P-Ex12-expressing cells compared to P-WT- and CTL-expressing MEFS. (E) Quantification of cell plate area covered by transduced MEFS shown in $D$.

expressing wild-type (P-WT) or mutant forms of PDGFR (P-Ex12) into NOD-SCID mice. In two separate experiments involving a total of five animals per group, no tumor growth was evident in 10 total mice carrying CTL or P-WT cells through 80 total days of followup; however, three of five animals implanted with P-Ex12-expressing cells formed tumors that reached maximum acceptable size between 28 and $75 \mathrm{~d}$ postimplantation (Fig. 4C). One additional animal in that cohort died without obvious tumor formation, and the carcass was removed before necropsy was performed. Whether the biallelic Cdkn2a deletion contributed to the tumor-forming capacity in the P-Ex12-expressing 10T1/2 cells is not known.

Histological analysis of two of the P-Ex12-driven tumors demonstrated a high-grade neoplasm based on nuclear atypia, frequent and abnormal mitotic figures, evidence for necrosis, and evidence by light microscopy of tumor invasion into neurovascular tissues and adjacent skeletal muscle, resembling a high-grade sarcoma (Fig. 4D). PCR confirmed retention of the 

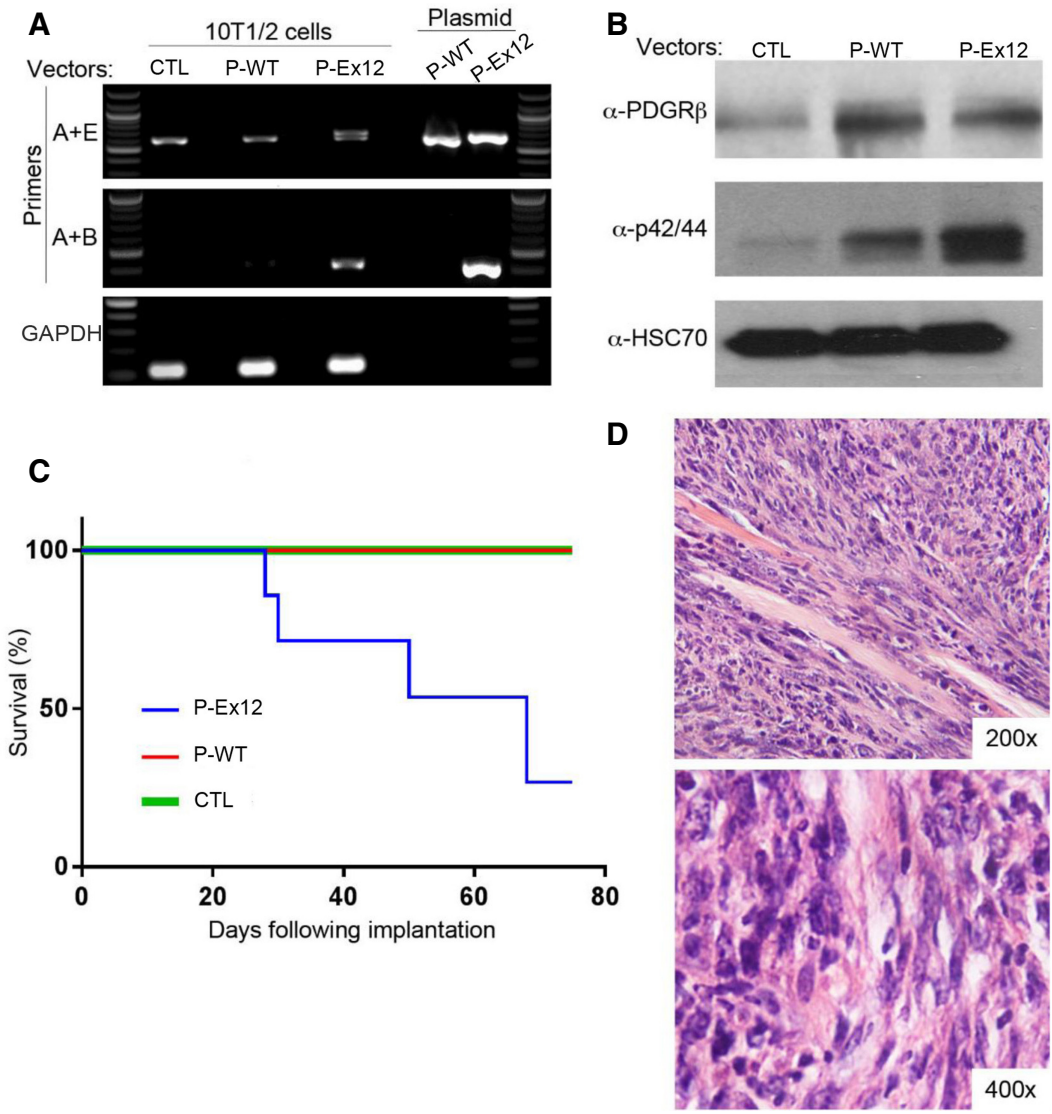

Figure 4. P-Ex12 is tumorigenic in 10T1/2 fibroblasts. (A) RT-PCR of 10T1/2 cells transduced with P-Ex12, P-WT, and CTL lentiviral vectors. (B) Representative western blot of 10T1/2 cells confirms expression of PDGFRB and increased expression of phospho-p44/42 MAPK of cells transduced with lentivirus bearing P-Ex12 as compared to P-WT- and CTL-expressing fibroblasts. (C) Kaplan-Meier plot displays decreased overall survival of mice bearing P-Ex12-transduced 10T1/2 cells compared to both CTL- and P-WT-transduced cells. (D) Histopathological examination of processed tumor samples show signs of tumor infiltration through nerve cells, blood vessels, and muscle cells and areas of necrosis (hematoxylin and eosin, 200x and $400 \times$ magnification).

P-Ex12 lentiviral vector (Fig. 5A), and immunostaining for both Ki67 and phospho-histone H3 demonstrated high proliferation (Fig. 5B).

Finally, we utilized the colony-forming assay in MEFs transduced with either P-WT- or PEx12-expressing vectors to test whether accumulation of the P-Ex12-expressing MEFs could be blunted by imatinib, a potent inhibitor of PDGFR $\beta$ and other tyrosine kinases (Arts et al. 2016). Indeed, the P-Ex12-expressing MEFs seemed even more susceptible to imatinib inhibition than MEFs expressing wild-type PDGFR (Fig. 6A,B; one-way ANOVA; $P=0.0002$ ). In a complementary assay, transduced MEFs cultivated in a 96-well plate showed the $\mathrm{IC}_{50}$ for imatinib in P-Ex12-expressing MEFs to be significantly lower than in MEFs expressing wildtype receptor $(0.226 \mu \mathrm{M}$ vs. $1.684 \mu \mathrm{M}, t$-test; $P=0.0012$; Fig. $6 \mathrm{C})$. We note that the magnitude of the effect of imatinib on P-Ex12-driven, low-density, colony formation (Fig. 6A,B) seems greater than the effect on P-Ex12-driven cell accumulation (Fig. 6C); this may indicate that P-Ex12 differentially influences those two processes. Because published pharmacokinetic analyses indicate that $1 \mu \mathrm{M}$ steady state imatinib is well within the levels reached in adult patients treated with standard doses of imatinib (400 mg) (Peng et al. 2004), we 


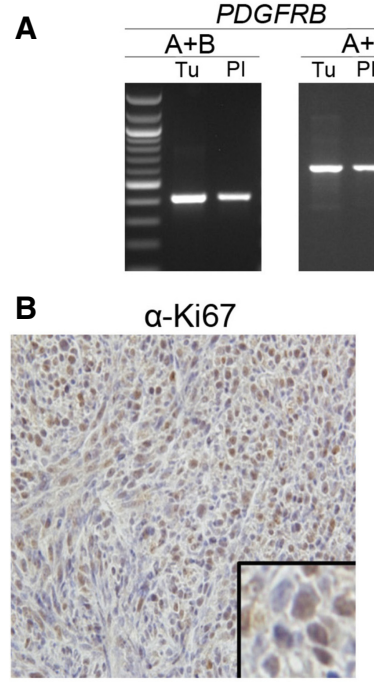

a-PH3
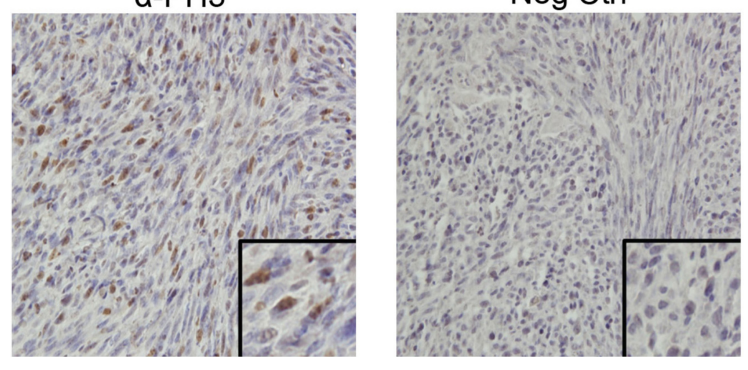

Figure 5. Analysis of tumors formed by 10T1/2 fibroblasts expressing the rearranged PDGFRB cDNA. (A) RT-PCR of tumor samples confirms expression of P-Ex12 in the tumor (Tu); plasmid (PI) used as control in PCR. (B) Immunohistochemistry staining of tumor samples shows positive staining for Ki67 ( $\alpha-K i 67)$ and phospho-histone H3 (a-PH3).

conclude that expression of the PDGFR $\beta$ variant with a disrupted inhibitory juxtamembrane domain represents a vulnerability that can be exploited therapeutically.

\section{DISCUSSION}

IM is a relatively rare neoplasm most recently classified by the World Health Organization as a pericytic tumor (Parham 2018), which is consistent with the concept that the tumor can be driven by activating mutations in PDGFRB, a gene required for pericyte accumulation in the mouse (Soriano 1994). The clinical presentation and course of IM can range from the presence of a single lesion that regresses spontaneously to multifocal, multiorgan disease which can represent a life-threatening problem (Fukasawa et al. 1994; Mashiah et al. 2014; Parham 2018). For those complex cases, systemic chemotherapy, including the use of vinblastine and methotrexate and other "low dose" cytotoxic agents, has demonstrated activity (Azzam et al. 2009; Weaver et al. 2015). The recognition that most cases of IM are associated with either somatic or germline mutations activating the PDGFR $\beta$ kinase has suggested the potential clinical utility of treatment using molecularly targeted agents, such as sunitinib and other kinase inhibitors (Arts et al. 2016; Agaimy et al. 2017; Sramek et al. 2018). It is therefore important to recognize more complicated rearrangements such as that seen in our patient as 
A
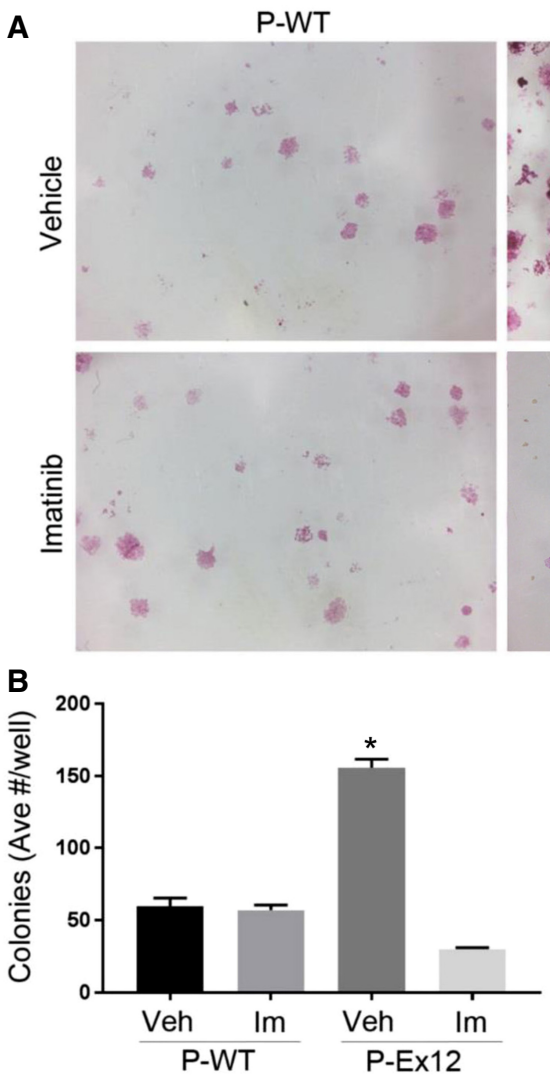

P-Ex12
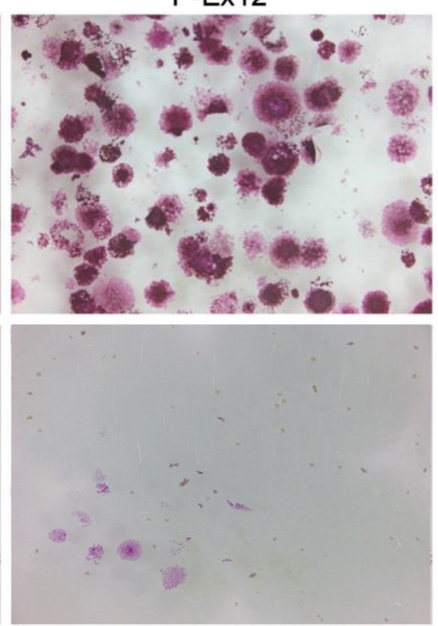

C

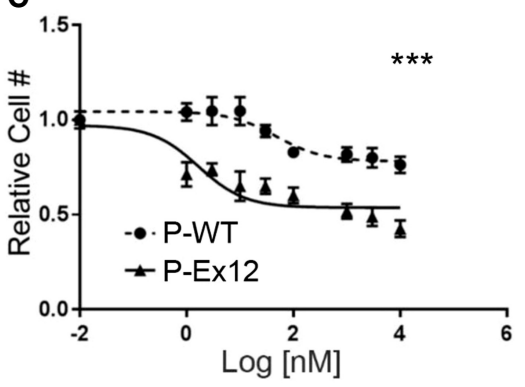

Figure 6. Treatment of transduced mouse embryonic fibroblasts. (A) Representative photographs of transduced PDGFRB-null mouse embryonic fibroblasts show increased colony formation with P-Ex12 expression that is blunted with imatinib treatment $(1 \mu \mathrm{M})$. (B) Quantification of colony formation in treated and untreated P-WT- and P-Ex12-transduced MEFs. (C) MEFs transduced with P-Ex12 demonstrate increased sensitivity to imatinib as compared to P-WT MEFs.

a potential mechanism by which PDGFR $\beta$ can be activated and subsequently targeted by molecular therapies. Such rearrangements may be missed by sequencing approaches that only evaluate for targeted hotspot mutations. Moreover, given that PDGFRB mutations are common in IM, but rare in infantile fibrosarcoma, which can be histologically similar (Alaggio et al. 2008), the identification of an oncogenic PDGFRB alteration may play a role in making the correct diagnosis.

The exact mechanism by which the rearrangement that we describe deregulates PDGFR $\beta$ will need to be elucidated in more detail in subsequent studies. However, given the inhibitory nature of the juxtamembrane domain and the presence of activating drugsensitive alterations disrupting that domain in other receptor tyrosine kinases such as FLT3, PDGFRa, and KIT, it seems likely that disrupting the juxtamembrane domain curtails an auto-inhibitory mechanism leading to the hyperactivation of the kinase domain (Kiyoi et al. 1998, 2002; Chan et al. 2003; Heinrich et al. 2003a,b; Corless et al. 2005; Corbacioglu et al. 2006; Reindl et al. 2006; Stover et al. 2006; Kim et al. 2011; Liang et al. 2016; Short et al. 2019). Previous studies have implicated Arg561 as a key residue for the inhibitory juxtamembrane-kinase domain interaction, and consistent with that model, Arg561 and flanking residues are replaced in the P-Ex12 protein (Fig. 2D; Cheung et al. 2013). Our data show that the P-Ex12 variant activates at least one downstream signaling pathway more robustly than the wild-type protein. Whether the P-Ex12 additionally activates a 
different set of signaling pathways than the ligand-stimulated wild-type receptor PDGFR $\beta$, harboring activating mutations, or PDGFRB rearrangements such as TEL-PDGFRB fusion is not clear at present (Golub et al. 1994). We also noted that the P-Ex12 form was generally found at a lower level than the wild-type protein, when both were ectopically expressed. We suspect that this may be due to differential posttranslational processing, such as ubiquitylation noted to traffic certain RTKs to the lysosome ${ }^{53}$, perhaps to help gait excess signaling. The concept needs experimental validation, as does the role of the p14ARF/ p16INK4A variants in this case.

An important takeaway from our study is that this new PDGFRB variant is not only transforming and able to drive cancer in xenografted mice but is also sensitive to clinical doses of imatinib (Fig. 6), suggesting that this widely available and approved agent can counteract the key PDGFR $\beta$-elicited oncogenic signaling in IM. Similarly, preclinical studies have demonstrated that many of the missense variants in PDGFRB which occur in IM are sensitive to inhibition by tyrosine kinase inhibitors, and a recent case report highlights the clinical utility of sunitinib, a PDGFR $\beta$ targeting multikinase inhibitor, in a patient with IM with a germline PDGFRB p.R561C mutation (Arts et al. 2016, 2017; Mudry et al. 2017). Although we only sequenced a single tumor from this patient, it is likely this represents a mosaic PDGFRB rearrangement explaining the patient's multifocal disease. Beyond mutations in PDGFRB, the limited number of mutations in other genes associated with IM also suggest that classical IM is a PDGFR $\beta$-driven disease, with alterations of NOTCH3 predicted to activate PDGFR $\beta$ and PTPRG, an enzyme that dephosphorylates PDGFR $\beta$ also reported in this disease (Martignetti et al. 2013; Linhares et al. 2014). The contribution of the CDKN2A variant to this child's disease or IM pathogenesis merits further exploration. Given the remarkable success of tropomyosin receptor kinase (TRK) inhibition for infantile fibrosarcoma (Laetsch et al. 2018), a disease histologically similar to IM and caused by activating fusions in the neurotrophic tyrosine kinase receptor (NTRK) family of genes, a clinical trial of PDGFR $\beta$ inhibition in patients with IM is warranted.

\section{METHODS}

Pathology and Molecular Analyses of Tumor Specimen

Routine histology processing and diagnostic studies were performed at Children's Health Children's Medical Center Dallas. Unstained formalin-fixed, paraffin-embedded (FFPE) tissue sections were analyzed using the Foundation One Heme panel (Foundation Medicine). In addition, RNA and DNA were extracted from fresh frozen tumor tissue using the AllPrep DNA/RNA Mini Kit (QIAGEN), according to the manufacturer's specifications. PCR and RT-PCR were carried out as previously described (Widau et al. 2012), using primers designed to amplify wild-type and mutated versions of human PDGFRB (Supplemental Table 1). The reactions were tested using gDNA and cDNA from U2OS and H290 cell lines, which express PDGFRB (Supplemental Fig. 1). PCR and RT-PCR products were run on a $0.8 \%$ agarose gel, purified using the QIAGEN QIAquick Gel Extraction Kit, and sequenced at the UTSW McDermott Sequencing Core. Sequencing was completed using Foundation One Heme panel (Foundation Medicine). The sequencing depth for the CDKN2A variant was $651 \times$ and the PDGFRB variant is shown in Table 2.

\section{Generating Lentiviral Vectors Expressing Either Wild-Type or Rearranged PDGFR $\beta$}

The rearranged PDGFRB cDNA amplified from the tumor specimen was digested using Fspl and Sacll and subcloned into pDONR221-hPDGFRB-WT, a Gateway entry clone containing 
Table 2. Sequencing coverage

\begin{tabular}{lcc}
\hline & Breakpoint \#1 & Breakpoint \#2 \\
\hline Duplication & $825 \times$ & $863 \times$ \\
Deletion & $797 \times$ & $991 \times$ \\
\hline
\end{tabular}

the human PDGFRB cDNA (Harvard PlasmID Repository), to generate pDONR221hPDGFRB- $\triangle E \times 12$. The cDNA encoding either P-WT and P-Ex12 was subcloned into the pLenti7.3 V5-DEST (Invitrogen) Gateway destination vector by LR recombination to produce lentiviral expression vectors in which CMV promoter drove expression of either P-WT or PEx12 as well as EmGFP, driven by the SV40 promoter (pLenti 7.3-hPDGFRB-WT and pLenti 7.3-hPDGFRB- $\Delta$ Ex12). Note that control vectors expressed only EmGFP. Plasmids were verified at each step of the process by PCR, restriction enzyme digestion, and bidirectional Sanger sequencing.

Lentiviral vector stocks were produced in HEK-293T cells using psPAX2 and pMD2.G packaging and envelope-expressing plasmids (Addgene). Cell culture supernatant was harvested after $48 \mathrm{~h}$, filtered using a $0.45 \mu \mathrm{m}$ filter, and stored in aliquots at $-80^{\circ} \mathrm{C}$. A lentiviral titer analysis was completed using 10-fold dilutions and analyzed for fluorescence by FACS analysis. Cells were subsequently transduced at a MOI of 1 and sorted by FACS analysis for GFP expression for functional experiments.

\section{Cell Culture}

Mouse embryonic fibroblasts (MEFs) were derived from Pdgfrb ${ }^{-1-}$ embryos harvested at embryonic day (E) 13.5 as products from mating heterozygous mice (Charles River Laboratories). Primary and subcultured MEFs were cultivated as previously described (Silva et al. 2005).

To assess colony-forming capacity, Pdgfrb ${ }^{-/-}$MEFs transduced to express CTL; P-WT and P-Ex12 were plated $\left(1 \times 10^{4}\right.$ cells $/ 100 \mathrm{~mm}$ plate or $2 \times 10^{3} /$ well of six-well plate) and cultivated for $14 \mathrm{~d}$. In some cases, cells were treated with of imatinib $1 \mu \mathrm{M}$ in DMSO (STI571 Catalog No. S2475) or an equivalent volume of DMSO as control. Cells were then fixed using $2 \%$ paraformaldehyde and stained with $0.05 \%$ crystal violet; photomicrographs were analyze using ImageJ or manual counting.

\section{Functional Evaluations}

\section{Ectopic mRNA and Protein Expression}

Pdgfrb $^{-/-}$MEFs or 10T1/2 fibroblasts were transduced, sorted by FACS analysis for GFP expression, and replated onto standard cell culture plates. Expression of P-WT and P-Ex12 was assessed by qRT-PCR or western blotting, essentially as previously described (Silva et al. 2005). RT-PCR primers were designed using the National Library of Medicine PRIMERBLAST tool, and obtained from Sigma-Aldrich. For western blotting, proteins were solubilized in RIPA lysis buffer supplemented with PhosStop Phosphotase inhibitor and Roche Complete Protease inhibitor (Roche). Primary antibodies recognized human and mouse PDGFRB (EMD Millipore, \#04-825), phospho-p42/44 (Cell signaling \#9102), total MAPK (Cell Signaling, 9102S), and HSC-70 (Santa Cruz SC-729). Secondary antibodies included anti-goat (Jackson ImmunoResearch 705-035-003), anti-rabbit (Jackson ImmunoResearch 111-035-003), and anti-mouse (Jackson ImmunoResearch 715-035-0150, and protein expression was detected by using both CareStream film (Sigma-Aldrich Z3730398) and BioRad Clarity Enhanced Chemiluminescence (Bio-Rad 1705060) 
COLD SPRING HARBOR Molecular Case Studies
PDGFRB rearrangement in infantile myofibromatosis

\section{Imatinib Sensitivity}

Pdgfrb $^{-/-}$MEFs ectopically expressing either P-WT or P-Ex12 were plated in a 96-well plate, exposed to imatinib at doses ranging from $1 \mathrm{nM}$ to $10 \mu \mathrm{M}$ for $5 \mathrm{~d}$, and analyzed by Cyquant (ThermoFisher Scientific C7026).

\section{Tumor-Forming Capacity}

10T1/2 fibroblasts transduced with control or experimental vectors expressing P-WT or PEx12 were expanded in vitro and harvested by trypsin/EDTA. Harvested cells $\left(25 \times 10^{7}\right)$ were suspended in equal parts phosphate-buffered saline and Matrigel (Corning 356237) and then implanted by subcutaneous injection into NOD-SCID mice (UTSW breeding core) with $5 \times 10^{6}$ cells/mouse. Tumor formation was assessed at least three times/week, and animals were euthanized by $\mathrm{CO}_{2}$ when tumor size approached $200 \mathrm{~mm}^{3}$ volume. Tumor specimens taken from euthanized animals were immediately bisected and either fixed in 4\% paraformaldehyde or processed and FFPE sectioning or flash frozen in LN2. DNA and protein were extracted from frozen tissue using QIAGEN DNA/RNA/Protein Mini Kit.

FFPE sections were stained using hematoxylin and eosin or by immunohistochemistry for Ki67 antibody (BD Pharmigen 556003) or phospho-histone H3 antibody (EMD Millipore 06570). Primary antibodies were detected using VectaStain Universal Quick Kit (Pk-8800).

\section{Statistical Analyses}

All quantitative analyses were carried out with two or more biological replicates and at least duplicate experiments were carried out on separate occasions. Quantitative differences were assessed using statistical tools, described in relevant figure legends.

\section{ADDITIONAL INFORMATION}

\section{Data Deposition and Access}

The PDGFRB variant has been submitted to ClinVar (https://www.ncbi.nlm.nih.gov/clinvar/) and can be found under accession number SCV000992360. We do not have permission to upload the raw clinical sequencing into a public repository.

\section{Ethics Statement}

The patient's legal guardian signed written informed consent and this study was approved by the institutional review board (IRB) at UT Southwestern Medical Center. Histological and molecular analyses of the human tumor specimen in this case was approved by the UT Southwestern Medical Center Institutional Review Board (protocol\# STU 022013-058). Animal studies were carried out with approval of the UT Southwestern Medical Center Animal Care and Use Committee (protocol \# APN-2015-101401).

\section{Acknowledgments}

The authors gratefully acknowledge the assistance of Amanda Richards, who is a clinical research coordinator employed in the Clinical Research Office of Children's Health Children's Medical Center Dallas, and technical assistance provided by the Animal Resources Center at UT Southwestern Medical Center. 
COLD SPRING HARBOR Molecular Case Studies
PDGFRB rearrangement in infantile myofibromatosis
Competing Interest Statement

T.W.L. discloses consulting for and research funding from Novartis Pharmaceuticals, outside the scope of this work.

Received May 23, 2019; accepted in revised form August 7, 2019.

\section{Author Contributions}

S.X.S., T.L., M.H., E.B., and R.W. were involved in conceptualization. D.R., A.R., T.L., L.L.Y., M.R., R.E., S.M.A., P.J.L., D.W.P., M.H., S.X.S., and R.W. were involved in data analyses. M.H., P.J.L., R.W., and Y.Z. were involved in in vivo and in vitro laboratory work. M.H., S.X.S., T.L., and E.B., were involved in writing, reviewing, and editing the manuscript.

\section{Funding}

This work was supported by a Multi-Investigator Research Award from the Cancer Prevention and Research Institute of Texas (RP120685 AC, P1, and P2) and by a gift to S.X.S. from the Patrick and Beatrice Haggerty Family Foundation to help support the characterization of oncogenic drivers in childhood cancer.

\section{REFERENCES}

Abe A, Emi N, Tanimoto M, Terasaki H, Marunouchi T, Saito H. 1997. Fusion of the platelet-derived growth factor receptor $\beta$ to a novel gene CEV14 in acute myelogenous leukemia after clonal evolution. Blood 90: 4271-4277.

Agaimy A, Bieg M, Michal M, Geddert H, Märkl B, Seitz J, Moskalev EA, Schlesner M, Metzler M, Hartmann A, et al. 2017. Recurrent somatic PDGFRB mutations in sporadic infantile/solitary adult myofibromas but not in angioleiomyomas and myopericytomas. Am J Surg Pathol 41: 195-203. doi:10.1097/PAS.00000 00000000752

Alaggio R, Barisani D, Ninfo V, Rosolen A, Coffin CM. 2008. Morphologic overlap between infantile myofibromatosis and infantile fibrosarcoma: a pitfall in diagnosis. Pediatr Dev Pathol 11: 355-362. doi:10.2350/0709-0355.1

Andrae J, Gallini R, Betsholtz C. 2008. Role of platelet-derived growth factors in physiology and medicine. Genes Dev 22: 1276-1312. doi:10.1101/gad.1653708

Arts FA, Chand D, Pecquet C, Velghe Al, Constantinescu S, Hallberg B, Demoulin JB. 2016. PDGFRB mutants found in patients with familial infantile myofibromatosis or overgrowth syndrome are oncogenic and sensitive to imatinib. Oncogene 35: 3239-3248. doi:10.1038/onc.2015.383

Arts FA, Sciot R, Brichard B, Renard M, de Rocca Serra A, Dachy G, Noël LA, Velghe Al, Galant C, DebiecRychter M, et al. 2017. PDGFRB gain-of-function mutations in sporadic infantile myofibromatosis. Hum Mol Genet 26: 1801-1810. doi:10.1093/hmg/ddx081

Azzam R, Abboud M, Muwakkit S, Khoury N, Saab R. 2009. First-line therapy of generalized infantile myofibromatosis with low-dose vinblastine and methotrexate. Pediatr Blood Cancer 52: 308. doi:10.1002/pbc .21797

Chan PM, Ilangumaran S, La Rose J, Chakrabartty A, Rottapel R. 2003. Autoinhibition of the kit receptor tyrosine kinase by the cytosolic juxtamembrane region. Mol Cell Biol 23: 3067-3078. doi:10.1128/MCB.23.9 .3067-3078.2003

Cheung YH, Gayden T, Campeau PM, LeDuc CA, Russo D, Nguyen VH, Guo J, Qi M, Guan Y, Albrecht S, et al. 2013. A recurrent PDGFRB mutation causes familial infantile myofibromatosis. Am J Hum Genet 92: $996-$ 1000. doi:10.1016/j.ajhg.2013.04.026

Corbacioglu S, Kilic M, Westhoff MA, Reinhardt D, Fulda S, Debatin KM. 2006. Newly identified c-KIT receptor tyrosine kinase ITD in childhood AML induces ligand-independent growth and is responsive to a synergistic effect of imatinib and rapamycin. Blood 108: 3504-3513. doi:10.1182/blood-2006-05-021691

Corless CL, Schroeder A, Griffith D, Town A, McGreevey L, Harrell P, Shiraga S, Bainbridge T, Morich J, Heinrich MC. 2005. PDGFRA mutations in gastrointestinal stromal tumors: frequency, spectrum and in vitro sensitivity to imatinib. J Clin Oncol 23: 5357-5364. doi:10.1200/JCO.2005.14.068

Day M, Edwards AO, Weinberg A, Leavey PJ. 2002. Brief report: successful therapy of a patient with infantile generalized myofibromatosis. Med Pediatr Oncol 38: 371-373. doi:10.1002/mpo.1350

di Tommaso A, Hagen J, Tompkins V, Muniz V, Dudakovic A, Kitzis A, Ladeveze V, Quelle DE. 2009. Residues in the alternative reading frame tumor suppressor that influence its stability and p53-independent activities. Exp Cell Res 315: 1326-1335. doi:10.1016/j.yexcr.2009.01.010

Forsberg K, Valyi-Nagy I, Heldin CH, Herlyn M, Westermark B. 1993. Platelet-derived growth factor (PDGF) in oncogenesis: development of a vascular connective tissue stroma in xenotransplanted human melanoma producing PDGF-BB. Proc Natl Acad Sci 90: 393-397. doi:10.1073/pnas.90.2.393

Fukasawa Y, Ishikura H, Takada A, Yokoyama S, Imamura M, Yoshiki T, Sato H. 1994. Massive apoptosis in infantile myofibromatosis. A putative mechanism of tumor regression. Am J Pathol 144: 480-485. 
Golub TR, Barker GF, Lovett M, Gilliland DG. 1994. Fusion of PDGF receptor $\beta$ to a novel ets-like gene, tel, in chronic myelomonocytic leukemia with $\mathrm{t}(5 ; 12)$ chromosomal translocation. Cell 77: 307-316. doi:10.1016/ 0092-8674(94)90322-0

Heinrich MC, Corless CL, Demetri GD, Blanke CD, von Mehren M, Joensuu H, McGreevey LS, Chen CJ, Van den Abbeele AD, Druker BJ, et al. 2003a. Kinase mutations and imatinib response in patients with metastatic gastrointestinal stromal tumor. J Clin Oncol 21: 4342-4349. doi:10.1200/JCO.2003.04.190

Heinrich MC, Corless CL, Duensing A, McGreevey L, Chen CJ, Joseph N, Singer S, Griffith DJ, Haley A, Town A, et al. 2003b. PDGFRA activating mutations in gastrointestinal stromal tumors. Science 299: 708-710. doi:10.1126/science.1079666

Hellström M, Kalen M, Lindahl P, Abramsson A, Betsholtz C. 1999. Role of PDGF-B and PDGFR- $\beta$ in recruitment of vascular smooth muscle cells and pericytes during embryonic blood vessel formation in the mouse. Development 126: 3047-3055.

Hoch RV, Soriano P. 2003. Roles of PDGF in animal development. Development 130: 4769-4784. doi:10 $.1242 /$ dev.00721

Kamijo T, Zindy F, Roussel MF, Quelle DE, Downing JR, Ashmun RA, Grosveld G, Sherr CJ. 1997. Tumor suppression at the mouse INK4a locus mediated by the alternative reading frame product p19ARF. Cell 91: 649-659. doi:10.1016/S0092-8674(00)80452-3

Kim SY, Kang JJ, Lee HH, Kang JJ, Kim B, Kim CG, Park TK, Kang H. 2011. Mechanism of activation of human cKIT kinase by internal tandem duplications of the juxtamembrane domain and point mutations at aspartic acid 816. Biochem Biophys Res Commun 410: 224-228. doi:10.1016/j.bbrc.2011.05.111

Kiyoi H, Towatari M, Yokota S, Hamaguchi M, Ohno R, Saito H, Naoe T. 1998. Internal tandem duplication of the FLT3 gene is a novel modality of elongation mutation which causes constitutive activation of the product. Leukemia 12: 1333-1337. doi:10.1038/sj.leu.2401130

Kiyoi H, Ohno R, Ueda R, Saito H, Naoe T. 2002. Mechanism of constitutive activation of FLT3 with internal tandem duplication in the juxtamembrane domain. Oncogene 21: 2555-2563. doi:10.1038/sj .onc. 1205332

Laetsch TW, DuBois SG, Mascarenhas L, Turpin B, Federman N, Albert CM, Nagasubramanian R, Davis JL, Rudzinski E, Feraco AM, et al. 2018. Larotrectinib for paediatric solid tumours harbouring NTRK gene fusions: phase 1 results from a multicentre, open-label, phase 1/2 study. Lancet Oncol 19: 705-714. doi:10 .1016/S1470-2045(18)30119-0

Liang L, Yan XE, Yin Y, Yun CH. 2016. Structural and biochemical studies of the PDGFRA kinase domain. Biochem Biophys Res Commun 477: 667-672. doi:10.1016/j.bbrc.2016.06.117

Linhares ND, Freire MC, Cardenas RG, Bahia M, Puzenat E, Aubin F, Pena SD. 2014. Modulation of expressivity in PDGFRB-related infantile myofibromatosis: a role for PTPRG? Genet Mol Res 13: 6287-6292. doi:10 .4238/2014.August.15.11

Magnusson MK, Meade KE, Brown KE, Arthur DC, Krueger LA, Barrett AJ, Dunbar CE. 2001. Rabaptin-5 is a novel fusion partner to platelet-derived growth factor $\beta$ receptor in chronic myelomonocytic leukemia. Blood 98: 2518-2525. doi:10.1182/blood.V98.8.2518

Martignetti JA, Tian L, Li D, Ramirez MC, Camacho-Vanegas O, Camacho SC, Guo Y, Zand DJ, Bernstein AM, Masur SK, et al. 2013. Mutations in PDGFRB cause autosomal-dominant infantile myofibromatosis. Am J Hum Genet 92: 1001-1007. doi:10.1016/j.ajhg.2013.04.024

Mashiah J, Hadj-Rabia S, Dompmartin A, Harroche A, Laloum-Grynberg E, Wolter M, Amoric JC, HamelTeillac D, Guero S, Fraitag S, et al. 2014. Infantile myofibromatosis: a series of 28 cases. J Am Acad Dermatol 71: 264-270. doi:10.1016/j.jaad.2014.03.035

McArthur GA. 2006. Dermatofibrosarcoma protuberans: a surgical disease with a molecular savior. Curr Opin Oncol 18: 341-346. doi:10.1097/01.cco.0000228739.62756.df

Mudry P, Slaby O, Neradil J, Soukalova J, Melicharkova K, Rohleder O, Jezova M, Seehofnerova A, Michu E, Veselska R, et al. 2017. Case report: rapid and durable response to PDGFR targeted therapy in a child with refractory multiple infantile myofibromatosis and a heterozygous germline mutation of the PDGFRB gene. BMC Cancer 17: 119. doi:10.1186/s12885-017-3115-x

Murray N, Hanna B, Graf N, Fu H, Mylène V, Campeau PM, Ronan A. 2017. The spectrum of infantile myofibromatosis includes both non-penetrance and adult recurrence. Eur J Med Genet 60: 353-358. doi:10 .1016/j.ejmg.2017.02.005

Pardee AB. 1989. G1 events and regulation of cell proliferation. Science 246: 603-608. doi:10.1126/science .2683075

Parham DM. 2018. Fibroblastic and myofibroblastic tumors of children: new genetic entities and new ancillary testing. F1000Res 7: F1000. doi:10.12688/f1000research.16236.1

Peng B, Hayes M, Resta D, Racine-Poon A, Druker BJ, Talpaz M, Sawyers CL, Rosamilia M, Ford J, Lloyd P, et al. 2004. Pharmacokinetics and pharmacodynamics of imatinib in a phase I trial with chronic myeloid leukemia patients. J Clin Oncol 22: 935-942. doi:10.1200/JCO.2004.03.050 
Pond D, Arts FA, Mendelsohn NJ, Demoulin JB, Scharer G, Messinger Y. 2018. A patient with germ-line gain-of-function PDGFRB p.N666H mutation and marked clinical response to imatinib. Genet Med 20: 142-150. doi:10.1038/gim.2017.104

Reindl C, Bagrintseva K, Vempati S, Schnittger S, Ellwart JW, Wenig K, Hopfner KP, Hiddemann W, Spiekermann K. 2006. Point mutations in the juxtamembrane domain of FLT3 define a new class of activating mutations in AML. Blood 107: 3700-3707. doi:10.1182/blood-2005-06-2596

Reznikoff CA, Brankow DW, Heidelberger C. 1973. Establishment and characterization of a cloned line of C3H mouse embryo cells sensitive to postconfluence inhibition of division. Cancer Res 33: 3231-3238.

Short NJ, Kantarjian H, Ravandi F, Daver N. 2019. Emerging treatment paradigms with FLT3 inhibitors in acute myeloid leukemia. Ther Adv Hematol 10: 2040620719827310. doi:10.1177/2040620719827310

Silva RL, Thornton JD, Martin AC, Rehg JE, Bertwistle D, Zindy F, Skapek SX. 2005. Arf-dependent regulation of Pdgf signaling in perivascular cells in the developing mouse eye. EMBO J 24: 2803-2814. doi:10.1038/ sj.emboj.7600751

Soriano P. 1994. Abnormal kidney development and hematological disorders in PDGF $\beta$-receptor mutant mice. Genes Dev 8: 1888-1896. doi:10.1101/gad.8.16.1888

Sramek M, Neradil J, Macigova P, Mudry P, Polaskova K, Slaby O, Noskova H, Sterba J, Veselska R. 2018. Effects of sunitinib and other kinase inhibitors on cells harboring a PDGFRB mutation associated with infantile myofibromatosis. Int J Mol Sci 19: E2599. doi:10.3390/ijms19092599

Stover EH, Chen J, Folens C, Lee BH, Mentens N, Marynen P, Williams IR, Gilliland DG, Cools J. 2006. Activation of FIP1L1-PDGFRa requires disruption of the juxtamembrane domain of PDGFRa and is FIP1L1-independent. Proc Natl Acad Sci 103: 8078-8083. doi:10.1073/pnas.0601192103

Tallquist M, Kazlauskas A. 2004. PDGF signaling in cells and mice. Cytokine Growth Factor Rev 15: 205-213. doi:10.1016/j.cytogfr.2004.03.003

Toffalini F, Demoulin JB. 2010. New insights into the mechanisms of hematopoietic cell transformation by activated receptor tyrosine kinases. Blood 116: 2429-2437. doi:10.1182/blood-2010-04-279752

Wang J, Hisaoka M, Shimajiri S, Morimitsu Y, Hashimoto H. 1999. Detection of COL1A1-PDGFB fusion transcripts in dermatofibrosarcoma protuberans by reverse transcription-polymerase chain reaction using archival formalin-fixed, paraffin-embedded tissues. Diagn Mol Pathol 8: 113-119. doi:10.1097/00019606199909000-00002

Weaver MS, Navid F, Huppmann A, Meany H, Angiolillo A. 2015. Vincristine and dactinomycin in infantile myofibromatosis with a review of treatment options. J Pediatr Hematol Oncol 37: 237-241. doi:10.1097/MPH .0000000000000286

Widau RC, Zheng Y, Sung CY, Zelivianskaia A, Roach LE, Bachmeyer KM, Abramova T, Desgardin A, Rosner A, Cunningham JM, et al. 2012. p1 $^{\text {Arf }}$ represses platelet-derived growth factor receptor $\beta$ by transcriptional and posttranscriptional mechanisms. Mol Cell Biol 32: 4270-4282. doi:10.1128/MCB.06424-11

Wiswell TE, Davis J, Cunningham BE, Solenberger R, Thomas PJ. 1988. Infantile myofibromatosis: the most common fibrous tumor of infancy. J Pediatr Surg 23: 315-318. doi:10.1016/S0022-3468(88)80196-9

Wu SY, McCavit TL, Cederberg K, Galindo RL, Leavey PJ. 2015. Chemotherapy for generalized infantile myofibromatosis with visceral involvement. J Pediatr Hematol Oncol 37: 402-405. doi:10.1097/MPH .0000000000000132 


\section{COLD SPRING HARBOR Molecular Case Studies}

\section{Novel PDGFRB rearrangement in multifocal infantile myofibromatosis is tumorigenic and sensitive to imatinib}

Mohammed Hassan, Erin Butler, Raphael Wilson, et al.

Cold Spring Harb Mol Case Stud 2019, 5: a004440

Access the most recent version at doi: $10.1101 / \mathrm{mcs} . a 004440$
Supplementary http://molecularcasestudies.cshlp.org/content/suppl/2019/10/22/mcs.a004440.D Material C1
References This article cites 51 articles, 20 of which can be accessed free at: http://molecularcasestudies.cshlp.org/content/5/5/a004440.full.html\#ref-list-1
License This article is distributed under the terms of the Creative Commons Attribution-NonCommercial License, which permits reuse and redistribution, except for commercial purposes, provided that the original author and source are credited.
Email Alerting Receive free email alerts when new articles cite this article - sign up in the box at the Service top right corner of the article or click here.

